\title{
International Cooperation on Climate-friendly Technologies
}

\author{
Rolf Golombek • Michael Hoel
}

Accepted: 1 December 2010 / Published online: 9 January 2011

(C) The Author(s) 2011. This article is published with open access at Springerlink.com

\begin{abstract}
We examine international cooperation on technological development as an alternative to international cooperation on emission reductions. We show that without any R\&D cooperation, R\&D in each country should be increased beyond the non-cooperative level if (i) the technology level in one country is positively affected by R\&D in other countries, (ii) the domestic carbon tax is lower than the Pigovian level, or (iii) the domestic carbon tax is set directly through an international tax agreement. We also show that a second-best technology agreement has higher R\&D, higher emissions, or both compared with the firstbest-outcome. The second-best subsidy always exceeds the subsidy under no international R\&D cooperation. Further, when the price of carbon is the same in the second-best technology agreement and in the case without $R \& D$ cooperation, welfare is highest, $R \& D$ is highest and emissions are lowest in the second-best R\&D agreement.
\end{abstract}

Keywords Climate policy $\cdot$ International climate agreements $\cdot R \& D$ policy $\cdot$ Technology spillovers

JEL Classification $\quad \mathrm{H} 23 \cdot \mathrm{O} 30 \cdot \mathrm{Q} 20 \cdot \mathrm{Q} 38 \cdot \mathrm{Q} 48 \cdot \mathrm{Q} 54$

\section{Introduction}

The Kyoto Protocol is the result of international negotiations over many years. If honored, it will reduce emissions in the period 2000-12 compared with 'Business-as-Usual' (BaU) emissions. There are, however, many weaknesses with the agreement; limited coverage,

R. Golombek

Frisch Centre, Gaustadalleen 21, 0349 Oslo, Norway

e-mail: rolf.golombek@frisch.uio.no

M. Hoel $(\bowtie)$

Department of Economics, University of Oslo, PO Box 1095, Blindern, Oslo 0317, Norway

e-mail: m.o.hoel@econ.uio.no 
moderate emission reductions requirements, and uncertainty whether there will be any follow-up after 2012, see, for example, Böhringer and Vogt (2003).

Because of the shortcomings of the 'Kyoto track', several observers have asked whether other types of agreements might be designed to support large reductions of GHG emissions. One idea that has been proposed is to focus not directly on emissions but instead on policies affecting emissions. An obvious candidate would be a common carbon tax, as discussed by, for example, Cooper (1998), Wiener (1999), Victor (2001), Victor and Coben (2005) and Golombek and Hoel (2006).

Another idea would be to focus on technology improvements in order to reduce abatement costs, as this might increase a country's willingness to undertake significant emission reductions. For example, it is beneficial to supplement a Kyoto type of agreement with technology elements if technological development depends not only on a country's own R\&D investment but also on R\&D by other countries through cross-country technology spillovers. Even with no explicit agreement on emissions, a technology agreement leading to increased $\mathrm{R} \& \mathrm{D}$, and thus to lower abatement costs, might result in a reduction in emissions. This is the background for the proposals of a climate agreement on technology development, see, for example, Barrett (2003, Sect. 15.13) and Barrett (2006).

In the present paper we examine international cooperation on technological development as an alternative to international cooperation on emission reductions. The basic idea of cooperating on technological development is to spur innovation and/or diffusion of climate-friendly technologies.

Cooperation on technological development may be designed in several ways. For example, it may commit governments to finance, or organize, basic research on a limited number of technologies, or to develop technology standards that all countries commit to impose domestically. Alternatively, countries may cooperate on policies directed toward private agents, for example, by providing instruments (e.g., technology subsidies or tax breaks) that foster more R\&D or increased application of new technologies. Cooperation on technological development may also seek to stimulate information sharing between firms by, for example, designing appropriate environments for research joint ventures: see Katsoulacos and Ulph (1998).

Below we focus on innovations by private firms that through economic instruments are encouraged to undertake $R \& D$. We assume that $R \& D$ leads to improved technology that decreases the marginal cost of emission reductions; this is the standard definition of environmental R\&D, see, for example, Milliman and Prince (1989), Jung et al. (1996), and Fischer et al. (2003).

Section 2 presents a model where there is a standard negative climate externality as well as a positive technology externality: each country's technology level increases not only as its own R\&D increases, but also as a consequence of increased R\&D in other countries through learning. We assume that each country's income is increasing in emissions and its technology level, which depends on R\&D expenditures in all countries. The social optimum, which is our reference case, is examined in Sect. 3. The first-best outcome can be reached by imposing the Pigovian tax (to correct for the climate externality) and a suitable technology subsidy (to correct for technology spillovers).

Our starting point (Sects. 4 and 5) is a situation where there is no cooperation on technological development: in each country the government sets an R\&D subsidy non-cooperatively. Further, in each country there is an exogenous carbon tax, assumed equal for all countries. The magnitude of the carbon tax rate reflects whether there is some cooperation on emissions, see the discussion below. For a given R\&D subsidy and a given carbon tax, profit maximizing firms determine $\mathrm{R} \& \mathrm{D}$ and emissions. 
We consider three cases for the exogenous carbon tax. First, the carbon tax is chosen noncooperatively, which implies that the tax will be set equal to a country's marginal climate cost. Second, countries participate in an international quota agreement with tradable permits. The domestic carbon tax rate will then be equal to the international quota price. Third, countries participate in an international tax agreement, that is, an agreement that dictates the domestic carbon tax to be used in all countries.

We assume that in each country only a fraction of the total returns to $R \& D$ are captured by the investing firms. Therefore, even without any international R\&D cooperation, it is optimal for each country to subsidize R\&D investment. However, in Sect. 6 we show that this non-cooperative subsidy is lower than the socially optimal subsidy if at least one of the following three conditions are satisfies: (i) there are positive cross-country spillovers (i.e., the technology level in one country is positively affected by R\&D in another country), (ii) the domestic carbon tax is lower than the Pigovian tax, that is, the sum of marginal climate costs of all countries, or (iii) the domestic carbon tax is set directly through an international tax agreement.

In Sect. 7 we analyze an international $R \& D$ agreement which specifies a second-best $R \& D$ subsidy to be implemented in all countries. This subsidy is determined by the group of all countries so as to maximize total welfare per country, taking into account how firms will respond to the agreement in the next stages of the game. Like in Sect. 5, there is a common (exogenous) carbon tax in all countries.

We find that the second-best subsidy, as well as the non-cooperative subsidy, depend on the exogenous carbon tax, and they tend to be lower the higher is the carbon tax. Yet, the second-best subsidy always exceeds the non-cooperative subsidy.

In Sect. 8 we compare the second-best technology agreement with the three cases without $R \& D$ cooperation - each case is characterized by an exogenous tax rate reflecting the degree/type of cooperation, see discussion above. When the domestic carbon tax is the same in the second-best technology agreement and the cases without R\&D cooperation, welfare is highest, $R \& D$ is highest and emissions are lowest in the second-best technology agreement.

In Sect. 8 we also introduce three types of agreements: a pure quota agreement is an agreement where quotas are set so that the carbon price is equal to the Pigovian level, but where there is no cooperation on R\&D policies. A pure tax agreement is an agreement where the carbon tax is set in the agreement, equal to the Pigovian level, but there is no cooperation on $R \& D$ policies. Finally, in a pure technology agreement the R\&D subsidy is chosen to maximize the social welfare of all countries, while the domestic carbon tax is at the non-cooperative level.

We show that if climate costs are negligible, both a pure quota agreement and a pure tax agreement have lower R\&D investment, higher emissions and lower welfare than a pure technology agreement. If instead technology spillovers are negligible, the rankings may be reversed. Finally, in Sect. 9 we discuss some of our simplifying assumptions and point at topics for future research.

\section{Spillovers and Technological Progress}

In this section we study how R\&D investment in one country affects the technology in other countries. Further, we formalize the relationship between the income of a country and total $R \& D$ expenditures, and derive an equilibrium relationship between R\&D investment and technology level at the country level. 


\subsection{Spillovers}

We assume that there are $n$ identical countries, and that each country invests in R\&D. The technology level $y$ of a particular country, henceforth referred to as the home country, is assumed to depend on its own R\&D investment $(x)$ and the amount of R\&D investment by other countries $\left(x^{*}\right) .{ }^{1}$ While technology spillovers allow a country to benefit from other countries' R\&D investment, only a part $\gamma$ (with $0<\gamma<1$ ) of other countries' R\&D investment is assumed beneficial for a country. Formally, the technology level of the home country $(y)$ is assumed given by

$$
y=x+\gamma(n-1) x^{*} .
$$

In (1) we have assumed an additive structure of technology spillovers, so that the technology level of a country depends on the sum of all countries' R\&D investment, corrected by the technology diffusion parameter $\gamma$. R\&D investments abroad, corrected by the technology diffusion parameter, are hence a perfect substitute for domestic R\&D investments. ${ }^{2}$

The technology level of a particular foreign country $\left(y^{*}\right)$ is determined-seen from the home country-in a similar way to (1):

$$
y^{*}=x^{*}+\gamma\left[x+(n-2) x^{*}\right] .
$$

In (2) the first term is $R \& D$ investment in the particular foreign country, while the terms in the square brackets are the spillover effect from the 'home' country plus the spillover effects from all other countries.

For the subsequent analysis, it is useful to derive a relationship between R\&D investment in one country and the technology levels of countries. From (1) and (2) we obtain

$$
x=h y+(H-h) y^{*}
$$

where the constants $h$ and $H$ are given by

$$
\begin{aligned}
h & =\frac{1+(n-2) \gamma}{1+(n-2) \gamma-(n-1) \gamma^{2}} \\
H & =\frac{1}{1+(n-1) \gamma} .
\end{aligned}
$$

It is straightforward to show that $0<H<1<h$. Moreover, $h$ is increasing in $\gamma$ while $H$ is declining in $\gamma$. For the limiting case of $\gamma=0$ we have $h=H=1$. Note that in an equilibrium with $y=y^{*}$, (3) reduces to

$$
x=H y .
$$

\subsection{Technological Progress}

We assume that each country's income is increasing - up to a limit - in its own emissions. Put differently, each country has an emission level that would follow from its optimization

\footnotetext{
1 With identical countries, R\&D investment will be equal in all countries in equilibrium. However, in order to find the equilibrium it is expedient to distinguish between $R \& D$ investment in a particular country and R\&D investment in the other countries.

2 The modeling assumption of linear spillovers goes back at least to Spence (1984). An alternative view is found in Cohen and Levinthal (1989), where it is argued that the ability of an agent to learn from others may depend on its own R\&D effort. Golombek and Hoel (2004) apply the ideas of Cohen and Levinthal on climate policy. Sena (2004) gives an overview of the (empirical) literature on knowledge spillovers.
} 
problem if the solution of this problem was made without considering the environmental impact of the emissions. This is often called the country's Business as Usual (BaU) emission level, and it will typically depend on the technology level of the country. Reducing emissions below the $\mathrm{BaU}$ level is costly: that is, it reduces the country's income.

Following Popp $(2004,2006)$, we formalize the cost of reducing emissions by the income function $R(e, y)$, where $e$ are emissions and $y$ is technology level. $R(e, y)$ is the aggregate income function of each country. The emission level that maximizes $R(e, y)$ is the $\mathrm{BaU}$ emission level, denoted $b(y) . R(e, y)$ is concave and differentiable, and for $e<b(y)$ the function $R(e, y)$ is increasing in both its arguments. We also assume that when $e<b(y)$, technology development reduces marginal abatement costs: that is, $R_{e y}<0$ for $e<b(y)$.

The main results in the present papers depend on $R_{e y}<0$. In our model $R_{e y}<0$ is a necessary condition to ensure that a profit maximizing firm will i) reduce its emissions if its technology level is increased, and ii) increase its technology level if the carbon price is increased. In the Appendix we explore under what conditions $R_{e y}<0$ for technology improvements that may lower carbon emissions. These are technology advances that either increase energy efficiency, or reduce costs of non-carbon energy, or reduce costs of carbon capture and storage (CCS). We argue that for these types of technology advances, $R_{\text {ey }}<0$ under reasonable assumptions.

\section{The Social Optimum}

Welfare of each country is given by net income $R(e, y)$ minus $\mathrm{R} \& \mathrm{D}$ expenditures and environmental costs. Below the unit cost of R\&D investment is normalized to 1 . Further, we let the marginal environmental cost for each country, $\delta$, be constant and identical across countries. Hence, the environmental damage of a country is $\delta n e$ in a symmetric equilibrium where each country has an emission level $e$. In the first-best social optimum, all firms must have the same emission level (e) as well as identical amounts of R\&D investment $(x)$. In this case total net benefits per country are therefore given by

$$
R(e, y)-H y-\delta n e
$$

where we have used $x=H y$, cf. (6). Maximizing (7) with respect to emissions $e$ and the technology level $y$ gives

$$
R_{e}(e, y)=n \delta
$$

and

$$
R_{y}(e, y)=H \text {. }
$$

Equation (8) is the standard requirement that marginal costs of abatement should equal the sum of marginal environmental costs for all countries, that is, the Pigovian level.

Rewriting (9) as $R_{y} H^{-1}=1$ gives us a straightforward interpretation of the second firstorder condition: the marginal benefits of R\&D investment when cross-country spillovers are taken into account $\left(R_{y} H^{-1}\right)$ should equal marginal costs of $\mathrm{R} \& \mathrm{D}$ investment (normalized to 1). We will later show that the first-best social optimum can be implemented through a suitable carbon $\operatorname{tax}(n \delta)$ and a suitable technology subsidy (see discussion after (22)). 


\section{Emissions and R\&D in a Four-stage Game}

We now analyze the market outcome when countries make individual decisions. The market outcome follows from a four-stage game, which determines emissions and R\&D in each country. The four stages can briefly be described as follows ${ }^{3}$ :

1. The government in each country sets an $R \& D$ subsidy (non-cooperatively or imposed through an international agreement)

2. R\&D in each country is determined by profit-maximizing firms

3. The government in each country sets a carbon tax

4. Emissions in each country are determined by profit-maximizing firms.

We start with stage 4 . In this stage the technology level $y$ is given from stage 2 and the carbon tax $t$ is given from stage 3. Because $R(e, y)$ is the income of a representative producer, profit-maximizing producers choose emissions in order to maximize $R(e, y)-t e$, giving

$$
R_{e}(e, y)=t .
$$

Equation (10) defines emissions as a function of the carbon tax and the technology level:

$$
e=e(t, y) \text {. }
$$

The assumption that $R(e, y)$ is strictly concave implies $e_{t}<0$, while $R_{e y}(e, y)<0$ implies that $e_{y}<0$.

In stage 3 each government chooses its carbon tax. We assume that this tax rate is identical in all (identical) countries, denoted $t$. Below we distinguish between three cases with respect to the carbon tax rate and how a single country evaluates emission reductions.

\section{Case 1: Non-Cooperative Decisions}

In case 1 the tax rate is chosen non-cooperatively. Hence, each country finds, using (10), the tax rate that maximizes $R(e, y)-\delta\left[e+(n-1) e^{*}\right]$ when emissions in all other countries, $e^{*}$, are taken as given. This gives the tax rate $t=\delta$, see Table 1 . When the tax rate is chosen non-cooperatively, each country evaluates emission reductions $(v)$ equal to its marginal environmental cost $(\delta)$. To sum up, under non-cooperative decisions we have $v=t=\delta$.

\section{Case 2: Quota Agreement}

In this case countries participate in an international quota agreement with tradable permits. The basic idea of a climate agreement is to internalize that own emissions have negative impact on the welfare of other countries. We therefore assume that the total amount of permits is set so that the corresponding international quota price exceeds the marginal environmental cost of each country, $\delta$. In addition, we assume that the international quota price is used as the domestic tax rate $t$. Hence, $t>\delta$.

Further, we assume that the international quota price might be less than $n \delta$, reflecting that countries, for various reasons, are not able to reach a fully optimal agreement, for example, because of incentives to free ride. Thus, $t \leq n \delta$. Finally, when a country participates in an international quota agreement, own emission can be increased by buying a quota. Hence, $v=t$. To sum up, under a quota agreement we have $\delta<v=t \leq n \delta$.

3 The assumption that R\&D investment is determined before emissions reflects the fact that it takes more time to change the technology level than emissions. 
Table 1 Domestic carbon taxes and valuation of own emissions

\begin{tabular}{lll}
\hline & Carbon tax $t$ & $\begin{array}{l}\text { Valuation of own } \\
\text { emissions } v\end{array}$ \\
\hline Non-cooperative decisions & $t=\delta$ & $v=t=\delta$ \\
Quota agreement & $\delta<t \leq n \delta$ & $v=t>\delta$ \\
Carbon tax agreement & $\delta<t \leq n \delta$ & $v=\delta<t$ \\
\hline
\end{tabular}

\section{Case 3: Carbon Tax Agreement}

In the last case there is an international agreement dictating the carbon tax to be imposed in each country. This tax might be less than $n \delta$, again reflecting that countries, for various reasons, are not able to reach a fully optimal international agreement. Thus, $\delta<t \leq n \delta$.

When a country participates in an international agreement that directly specifies the domestic carbon tax, it is reasonable that the country valuates reduced emissions only by the effect lower emissions have on the country's own climate costs, that is, $v=\delta$. To sum up, under a carbon tax agreement we have $\delta=v<t \leq n \delta$.

Table 1 summarizes the discussion above. ${ }^{4}$ As seen from the Table, evaluation of own emissions equals the marginal climate cost, except under a quota agreement where evaluation equals the quota price. For all cases we assume that all countries use the same tax rate and have the same valuation of emissions (since countries are identical).

In stage 2 the producers in each country choose $x$ to maximize their profits, taking the $\mathrm{R} \& \mathrm{D}$ subsidy rate, denoted $\sigma$, as given from stage 1 . If there were no imperfections in the markets for innovations, then $R(e, y)-(1-\sigma) x-t e$ is maximized, taking R\&D in other countries $\left(x^{*}\right)$ as given. Using (1), (10) and (11), we obtain $R_{y}(e, y)=1-\sigma$.

The discussion above assumes that private firms capture the full social benefit of their R\&D investments. However, according to Popp (2006), several empirical studies suggest that the social returns to $R \& D$ are about four times higher than the private returns. The difference reflects—seen from the perspective of a single firm—various "imperfections" like limited intellectual property rights.

Below we do not model the equilibrium relationship between private and social returns to R\&D. ${ }^{5}$ Instead we simplify and consider the outcome of R\&D decisions, assuming that a firm is able to capture only a fraction $k$ of the entire social value of its successful R\&D investment. Hence, whereas $R_{y}(e, y)$ is the social value of $\mathrm{R} \& \mathrm{D}$ investment, $k R_{y}(e, y)$ is the private value accruing to the firm investing in $\mathrm{R} \& \mathrm{D}$ and hence $(1-k) R_{y}(e, y)$ is the value accruing to all other firms. The first-order condition for a firm wrt. $R \& D$ is therefore

$$
k R_{y}(e, y)=1-\sigma
$$

where $k$ is assumed to be identical across countries. Together with (10) this gives

$$
y=y(\sigma, t) .
$$

The assumption that $R(e, y)$ is strictly concave implies $y_{\sigma}>0$, while $R_{e y}(e, y)<0$ combined with $R(e, y)$ being strictly concave implies that $y_{t}>0$. Whereas we have not explicitly

\footnotetext{
4 Another possible case is that each country has some type of altruism, implying that it (partly) internalizes the climate costs of other countries. We leave it to the reader to examine this case.

5 This relationship can be modelled along the same line as the modelling of spillovers and technology level in Sect. 2.
} 
included $k$ in the function for $y$, the concavity of $R(e, y)$ implies that $y$ is higher the higher is $k$.

For the foreign countries we correspondingly have (remembering that the carbon tax is assumed to be the same in all countries)

$$
y^{*}=y\left(\sigma^{*}, t\right) \text {. }
$$

We are now ready to proceed to the first stage of the game. The case of non-cooperatively determination of the R\&D subsidy is examined in Sects. 5 and 6 , whereas the R\&D subsidy being determined through an international technology agreement is studied in Sect. 7.

\section{Non-cooperate Determination of R\&D Subsidies}

Above we introduced three carbon tax policy rules, see Table 1. Because these rules are exogenous, the carbon tax in stage 3 is assumed to be independent of the technology levels. It then follows from (13) and (14) (and $y_{\sigma}>0$ ) that the technology levels are uniquely determined by the subsidy rates. A game of choosing subsidy rates is therefore equivalent to a game of choosing technology levels, and below we let countries choose their own technology level, taking the technology level of other countries $\left(y^{*}\right)$ as given. Hence, our (home) country maximizes

$$
R(e, y)-\left[h y+(H-h) y^{*}\right]-v e
$$

w.r.t. $y$, where we have used (3) and $v$ is the country's valuation of own emissions, see the discussion related to Table 1. Maximization of (15) and using (10) gives the first-order condition for the technology level:

$$
R_{y}(e, y)=h+(t-v)\left(-e_{y}(t, y)\right) .
$$

Together with (12), i.e., $k R_{y}(e, y)=1-\sigma$, we find the optimal subsidy

$$
\sigma=1-k\left[h+(t-v)\left(-e_{y}(t, y)\right)\right] .
$$

When emissions are evaluated at the same rate as the carbon tax, i.e., $v=t$, we have

$$
\sigma=1-k h<1-k \text { for } v=t .
$$

Note that this expression gives the equilibrium subsidy whenever $v=t$, i.e., for the two first cases in Table 1 (non-cooperative decisions or quota agreement). As usual, $k<1$ (firms are not capturing the full return to $R \& D$ investment) tends to make the subsidy positive, while $h>1$ tends to make it negative (i.e., a tax on $\mathrm{R} \& \mathrm{D}$ ). The latter effect represents the incentive for each country to free ride on $R \& D$ of other countries instead of doing $R \& D$ themselves. As seen from (17), the subsidy is negative if $\frac{1}{k}-h<(t-v)\left(-e_{y}(t, y)\right)$.

If we instead have the third case in Table 1 (carbon tax agreement), that is, $v=\delta<t$, each country would choose the subsidy

$$
\sigma=1-k\left[h+(t-\delta)\left(-e_{y}(t, y)\right)\right]<1-k h<1-k \quad \text { for } v=\delta<t .
$$

In this case the equilibrium subsidy is lower the higher is the carbon tax, at least if $-e_{y t}(t, y)>$ $0 .^{6}$ The reason is that each country is now committed to impose a carbon tax on its firms that exceeds its own evaluation of increased emissions $(t>v=\delta)$. Thus, the tax tends to provide

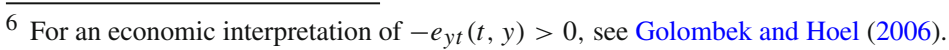


too much abatement relative to what is optimal for a county based on its pure self interest. A country will partly adjust for this affect through a low technology subsidy to its firms, which tends to reduce the technology level of the country. Under our assumption $R_{e y}<0$, marginal cost of abatement will now increase (because $y$ has been reduced), and hence emissions will be raised. A higher tax is therefore compensated by a lower technology subsidy.

As seen from (19), the subsidy is lower i) the more the imposed tax rate exceeds the country's evaluation of increased emissions, i.e., the higher is $(t-\delta)$ when $v=\delta$, ii) the more emissions respond to a higher technology level, i.e., the higher is $\left(-e_{y}\right)$, iii) the more private firms capture of the returns to $\& \& D$, i.e., the higher is $k$, and iv) the higher is the rate of diffusion, i.e., the higher is $\gamma$ and thus $h$, see the discussion after (5).

The term in the square bracket in (19) is larger than 1 for all $t \in[\delta, n \delta]$ due to $h>1$. From (18) and (19) we thus have the following proposition:

Proposition 1 The non-cooperative $R \& D$ subsidy rate is always lower than $1-k$, and may even be negative (i.e., an $R \& D$ tax). If countries value reduced emissions by the carbon tax rate $(v=t)$, the non-cooperative subsidy is $1-k h$. If countries instead value reduced emissions by its marginal environmental cost $\delta$ and $t>\delta$ (countries participate in an international carbon tax agreement), the non-cooperative subsidy is lower than $1-k h$.

\section{The Benefits of Improved Technology}

So far we have studied the four-stage game when the government in each country sets an R\&D subsidy non-cooperatively. Before examining the case where the R\&D subsidy is determined in an optimally designed international agreement (Sect. 7), we consider the more modest goal of increasing R\&D in all countries compared with the case without any cooperation on R\&D.

A common increase in $R \& D$ will give all countries an increase in their technology level $y$ relative to the non-cooperative outcome. Using (16), the benefit for each country of a small increase in $y$ is

$$
\Delta=R_{y}(e, y)-H+(n \delta-t)\left(-e_{y}(t, y)\right)=h-H+(n \delta-v)\left(-e_{y}(t, y)\right)
$$

which is positive since $h>H, n \delta \geq v$, and $e_{y}<0$. The benefits of improved technology are thus greater:

- the greater is $h-H$, which is increasing in the international diffusion parameter $\gamma$

- the greater is the term $n \delta-v$. If $v=\delta$ (carbon tax agreement), this term is simply equal to $(n-1) \delta$. If $v=t$ (non-cooperative decisions or quota agreement), then $n \delta-v=n \delta-t$, which is higher the lower is the carbon tax $t$

- the more emissions are reduced as a consequence of improved technology $\left(-e_{y}\right)$.

According to the second bullet point, under a carbon tax agreement it is beneficial to increase the R\&D level, and this is the case independent of the magnitude of the imposed tax.

From (20) we see that unless $v=t=n \delta$ (full internalization of the climate costs of other countries through a carbon tax agreement or a quota agreement), and there are no crosscountry technology spillovers $(h=H)$, it is welfare improving to increase R\&D investment beyond the non-cooperative level if $e_{y}<0$, i.e., if $R_{e y}(e, y)<0$. Finally, in the case of full internalization of other countries' climate costs and no cross-country technology spillovers, the equilibrium coincides with the first-best outcome, which of course cannot be improved upon. 


\section{An International Technology Agreement}

In this section we analyze an international agreement which regulates technology policies - we assume that the agreement specifies a common R\&D subsidy to be implemented in all countries. The subsidy is determined by the group of all countries so as to maximize total welfare per country, taking into account how firms will respond to the agreement in the next stages of the game. Because the first-best outcome cannot be reached within such an agreement (see below), the chosen subsidy is a second-best subsidy. Due to (13) and (14), choosing a common subsidy is equivalent to choosing a common technology level (when the choice of the common carbon tax rule is assumed independent of the technology level). Below we therefore find the technology level $y$ that maximizes total welfare per country, given by (7), subject to the constraint $e=e(t, y)$, see (11). The first-order condition of this problem is (using (10)):

$$
R_{y}=H+(n \delta-t) e_{y} \leq H .
$$

Using (12), we find that in order to obtain this outcome the second-best subsidy must be given by

$$
\sigma=1-k\left[H-(n \delta-t)\left(-e_{y}(t, y)\right)\right]>1-k .
$$

If the carbon tax is at the Pigovian level $t=n \delta$, the optimal subsidy is $1-k H$. Using (8), (9) and (12), we see that the first-best social outcome is now achieved. Below we therefore term $1-k H$ the first-best subsidy. The discussion above leads to the following Proposition:

Proposition 2 In an international technology agreement, the second-best $R \& D$ subsidy is higher than $1-k$, and thus higher than the non-cooperative subsidy. If the carbon tax is at the Pigovian level $t=n \delta$, the optimal subsidy is $1-k H$, and the first-best social optimum is achieved.

Proposition 2 and (22) imply that the second-best R\&D subsidy will be higher than the first-best subsidy $1-k H$ if $t<n \delta$. Moreover, the first-best R\&D subsidy $1-k H$ is higher than the non-cooperative $\mathrm{R} \& \mathrm{D}$ subsidy (because $H<1$ ), cf. Proposition 1 . These results tend to suggest that R\&D investment, and hence the technology level, is higher under a second-best technology agreement than in the first-best outcome, and also that the technology level is higher in the first-best outcome than in the case without any R\&D agreement. One should, however, be careful because the ranking of technology level does not follow directly from the R\&D subsidy rate; it also depends on how emissions are determined. We consider this issue in the next section.

\section{Comparison of Emissions and R\&D}

In the previous sections we have considered five outcomes, namely the first-best social optimum (Sect. 4), three cases with an exogenous carbon tax and non-cooperative determination of R\&D (Sect. 5) and an international technology agreement with an exogenous carbon tax (Sect. 7). In this section we compare these cases.

In Fig. 1 we have drawn the two curves representing $R_{e}(e, y)=n \delta$ and $R_{y}(e, y)=H$, corresponding to Eqs. (8) and (9). It is easily verified that the properties of the function $R(e, y)$ imply that these two curves are downward sloping in the $(e, y)$ diagram and that $R_{e}(e, y)=n \delta$ is steeper than $R_{y}(e, y)=H$. At the intersection point $F$ of these two curves, both Eqs. (8) and (9) hold, so this point represents the first-best social optimum. 


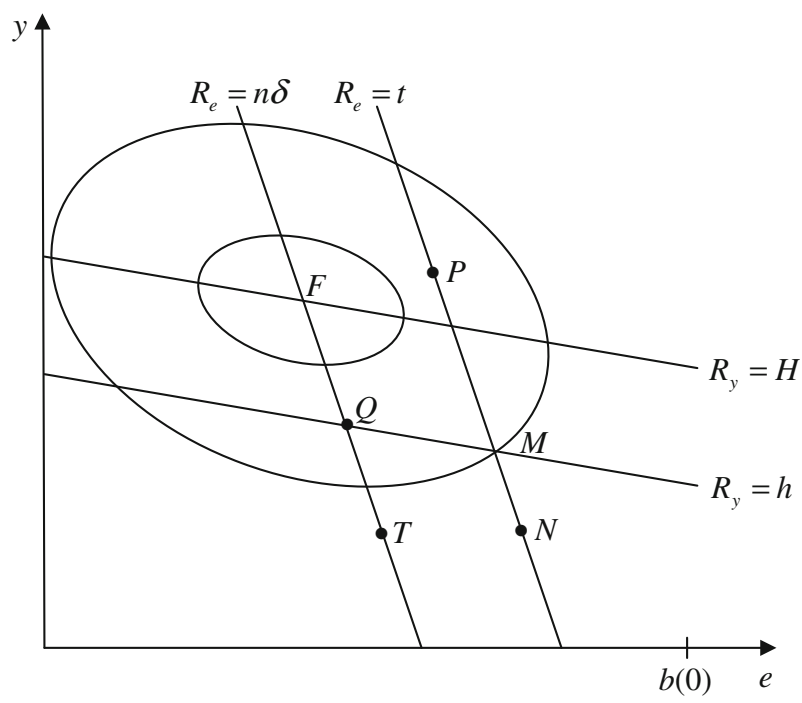

Fig. 1 Welfare ranking of international environmental agreements

In Fig. 1 we have also drawn two iso-welfare curves. Along each such curve net benefits of each country — given by (7) — are constant, and net benefits are higher the closer the curve is to the maximum point $F$. From the conditions (8) and (9) of the first-best social optimum, it follows that the iso-welfare curves are horizontal at the intersections with $R_{e}(e, y)=n \delta$, and vertical at the intersections with $R_{y}(e, y)=H$.

We have also drawn curves for $R_{e}(e, y)=t<n \delta$ (relation (10)) and $R_{y}(e, y)=h$ in Fig. 1. Because $n \delta>t$, the curve $R_{e}(e, y)=t$ must lie to the right of the curve $R_{e}(e, y)=n \delta$. Similarly, since $H<h$, the curve $R_{y}(e, y)=h$ must lie below the curve $R_{y}(e, y)=H$.

Because relation (10) is valid both with and without cooperation on $R \& D$, these equilibria are located somewhere on the line $R_{e}(e, y)=t$. Notice that the exact position of this curve depends on $t$, and will lie further to the left the higher is $t$. Without cooperation on R\&D, the equilibrium condition for R\&D is given by (16), and we have to distinguish between our three cases, see Table 1.

With non-cooperative decisions as well as under a quota agreement, emission reductions are valued by the domestic carbon tax $(v=t)$. Then (16) is reduced to $R_{y}(e, y)=h$, and these two cases are therefore represented by point $M$ in Fig. 1. Under a carbon tax agreement $t>v$, and from (16) we then have $R_{y}(e, y)>h$. Hence, point $N$ in Fig. 1 represents the case of an international tax agreement. Notice that $N$ coincides with $M$ for the limiting case of $t=\delta$. Comparing $M$ or $N$ with $F$ we have the following:

Proposition 3 Emissions are higher and $R \& D$ lower in the case of no cooperation on $R \& D$ than in the first-best social optimum.

Under an international technology agreement R\&D is determined by (21), implying that $R_{y}(e, y)<H$. Hence, the equilibrium must be somewhere above the curve $R_{y}(e, y)=H$. Because $R_{e}(e, y)=t$ is valid also in this equilibrium, in Fig. 1 point $\mathrm{P}$ represents the equilibrium under a technology agreement.

In Fig. 1, emissions and the technology level are higher in $P$ than in $F$ (first-best outcome). However, this ranking depends on the way we have drawn the curves in Fig. 1. In general, 
several rankings are possible. For example, the technology level may be lower and emissions higher in $P$ than in $F$. However, from Fig. 1 we see that if emissions are lower in $P$ than in $F$, then the technology level is higher in $P$ than in $F$.

From (21) we see that $P$ lies closer to the line $R_{y}(e, y)=H$ the (i) smaller is $n \delta-t$, and (ii) the smaller is $-e_{y}$. If $t=n \delta$, then $R_{y}=H$ and $P$ coincides with $F$. If $e_{y} \approx 0-$ reflecting that $R_{e y} \approx 0$ - along the curve $R_{e}=t$, then $R_{y} \approx H$ and $P$ is located southeast of $F$.

To sum up:

Proposition 4 The ranking of $R \& D$ investment and emissions between the second-best technology agreement and the first-best outcome is in general ambiguous. If the Pigovian tax is used in each country under a technology agreement, the first-best outcome is reached. If $R_{\text {ey }} \approx 0$ along the curve $R_{e}=t, R \& D$ investment will be lower and emissions will be higher under a second-best technology agreement than in the first-best outcome.

We can also use Fig. 1 to compare $M / N$ (no R\&D cooperation) with $P$ (an R\&D agreement) when the domestic carbon tax $t$ is the same in these equilibria, that is, when the equilibria are located on the same line $R_{e}(e, y)=t$. We immediately get the following result:

Proposition 5 For any given domestic carbon price $t$, an $R \& D$ agreement gives higher welfare, higher $R \& D$ and lower emissions than the case of $R \& D$ policies being determined non-cooperatively. Moreover, with non-cooperative $R \& D$ policies the second-best carbon tax agreement (point $N$ in Fig. 1) has lower welfare, lower $R \& D$ and higher emissions than the second-best quota agreement (point M in Fig. 1) when t is the same in the two cases.

The case of no agreement whatsoever is given by the point $M$ in Fig. 1 for $t=\delta$. Starting from this point and introducing an international quota agreement with a carbon price equal to the Pigovian level $(t=n \delta)$, but without introducing R\&D cooperation, will move the equilibrium to $Q$ in Fig. 1, which we term a pure quota agreement. From Fig. 1 it is clear that the move from $M$ to $Q$ increases welfare, increases R\&D and reduces emissions.

If we instead, starting from point $M$ in Fig. 1 for $t=\delta$, had introduced R\&D cooperation without any cooperation on emissions, henceforth termed a pure technology agreement, we would move from $M$ to $P$ (for $t=\delta$ ), which increases welfare, increases R\&D and reduces emissions.

Finally, starting from point $M$ in Fig. 1 for $t=\delta$ and introducing an international tax agreement where $t=n \delta$, henceforth termed a pure tax agreement, will move the equilibrium to $T$ in Fig. 1 .

We now compare the pure quota agreement $(Q)$, the pure technology agreement $(P)$ and the pure tax agreement $(T)$. In Fig. $1, P$ has higher R\&D and higher emissions than $Q$. While this seems plausible, it does not hold as a general result. We now show that $P$ may have higher R\&D or higher emissions than the equilibrium $Q$, and that the welfare ranking can go either way. We start with the welfare ranking.

In the limiting case of (almost) no technology spillovers, that is, $\gamma \approx 0$ and thus $h \approx H \approx 1$ (see the discussion after (5)), the two lines $R_{y}=H$ and $R_{y}=h$ will (almost) coincide. Hence, $Q$ will (almost) coincide with $F$, implying that welfare is higher under $Q$ than under $P$. On the other hand, for the limiting case of (almost) no concern for the environment, that is, $\delta \approx n \delta \approx 0$ and hence $t \approx n \delta, \quad P$ will (almost) coincide with $F$, implying that welfare is higher under $P$ than under $Q$. These two cases have an obvious interpretation: if there are two externalities, the welfare gain of correcting only one of them is largest when one corrects the most important one. In the limiting cases above, one of the externalities was negligible. 
Consider again the limiting case of (almost) no technology spillovers $(\gamma \approx 0)$, that is, when $Q$ (almost) coincides with $F$. Assume moreover that $R_{e y} \approx 0$ for emissions along the curve $R_{e}=\delta$. Then $e_{y}=\frac{-R_{e y}}{R_{e e}} \approx 0$, and using (21) $P$ will (almost) be on the curve $R_{y}=H$. If $R_{e y}<0$ for emissions to the left of the curve $R_{e}=\delta$, then the curve $R_{y}=H$ will be downward sloping to the left of the curve $R_{e}=\delta$ (as in Fig. 1). In this case $P$ must lie southeast of $F$, and therefore also southeast of $Q$ since $Q$ (almost) coincides with $F$. This is thus an example of a pure R\&D agreement giving lower R\&D and higher emissions than a pure quota agreement. Next, consider the limiting case of (almost) no concern for the environment $(\delta \approx n \delta \approx 0)$, that is, $P$ (almost) coincides with $F$. In this case $P$ will be located to the northwest of $Q$. This is thus an example of a pure $\mathrm{R} \& \mathrm{D}$ agreement giving higher R\&D and lower emissions than a pure quota agreement.

As seen from Fig. 1, a pure quota agreement has higher R\&D, lower emissions and higher welfare than a pure tax agreement. These results are covered in the last part of Proposition 5. We now compare a pure technology agreement with a pure tax agreement. Assume that $\gamma \approx 0$ (and thus $h \approx H$ ) and that $R_{e y} \approx 0$ (and thus $e_{y} \approx 0$ ) along the curves $R_{e}=\delta$ and $R_{e}=n \delta$, whereas $R_{e y}<0$ between these curves. Then $T$ will (almost) coincide with $F$ whereas $P$ will be located southeast of $F$ on the curve $R_{y}=H$. Therefore, R\&D investment will be higher, emissions will be lower and welfare will be higher under $T$ than under $P$. If $\delta \approx n \delta \approx 0, P$ will (almost) coincide with $F$ whereas $T$ will (almost) coincide with $Q$ (because $v=\delta \approx n \delta=t$, i.e., $v \approx t$ ), implying that welfare is higher under $P$ than under $T$.

The results above are summarized in the following Proposition:

Proposition 6 The ranking of social welfare, $R \& D$ investment and emissions between the pure technology agreement, the pure quota agreement and the pure tax agreement is in general ambiguous. If climate costs are sufficiently low, both a pure quota agreement and a pure tax agreement have lower $R \& D$ investment, higher emissions and lower welfare than a pure technology agreement. If instead technology spillovers are sufficiently small, the rankings may be opposite.

Note that $R_{e y} \approx 0$ along the curves $R_{e}=\delta$ and $R_{e}=n \delta$ implies that these curves are almost vertical in Fig. 1. If $R_{e y}=0$ everywhere, then $R_{e}=\delta$ and $R_{e}=n \delta$ are vertical and $R_{y}=H$ and $R_{y}=h$ are horizontal. For this special case we have the following proposition:

Proposition 7 If $R_{\text {ey }}=0$, a pure technology agreement has the same technology level as the first-best outcome, but higher emissions. The pure quota agreement coincides with the pure tax agreement, and these agreements have a lower technology level, but the same emission level, as the first-best outcome.

\section{Concluding Remarks}

The aim of the present paper is to improve our understanding of the incentives to invest in climate-friendly R\&D and to abate under different institutional arrangements. ${ }^{7}$ We seek to identify the main forces at work when improved technology lowers costs of abatement.

\footnotetext{
7 So far, there has been one initiative focusing on international cooperation on climate-friendly technologies - the Asia Pacific Partnership on Clean Development and Climate (APP) — which aims at accelerating the development and deployment of clean energy technologies through expanding investment and trade in cleaner energy technologies. To the best of our knowledge, the results of APP, where Australia, Canada, China, India, Japan, South Korea and the United States are the partners, remain to be seen.
} 
Our modelling strategy is to study these forces within the simplest possible framework. Below we discuss some of our simplifying assumptions, arguing that whereas the exact formulas derived in the present paper clearly depend on these assumptions, our main results can be generalized.

First, we have assumed that R\&D was undertaken by private firms and could be influenced by the government through an R\&D subsidy. However, our conclusions would be similar if we interpret $R \& D$ as being directly financed by the government. As noted in Sect. 5, a game of choosing R\&D subsidy rates is equivalent to a game of choosing technology levels. Moreover, with cooperation over R\&D, the equilibrium condition $x=H y$ implies that choosing $y$ (via a common subsidy rate) or choosing $x$ directly gives exactly the same outcome. The second-best technology agreement is thus the same if $\mathrm{R} \& \mathrm{D}$ is set directly by governments or indirectly through the choice of a common $\mathrm{R} \& \mathrm{D}$ subsidy.

We now argue that also for the case of no R\&D cooperation, our results are not qualitatively changed if $R \& D$ is not determined indirectly through a subsidy, but directly by the government. The home country was assumed to chose its technology level $y$ (via a subsidy rate) in order to maximize $R(e, y)-\left[h y+(H-h) y^{*}\right]-v e$, taking $y^{*}$ as given. This problem has (16) as its first-order condition. Assume now that R\&D is not determined indirectly through a subsidy, but directly by the government. Inserting (1) and (3) into (15), we find that the net benefit of a country is given by $R\left(e, x+\gamma(n-1) x^{*}\right)-x-v e$. Maximizing this expression w.r.t. $x$, taking $x^{*}$ as given, yields $R_{y}(e, y)=1+(t-$ $v)\left(-e_{y}(t, y)\right)$, which is almost identical to (16), the only difference being that $h$ is replaced by 1 . However, our main results are unaffected: Propositions 1 and 2 (about subsidy rates) are no longer relevant, while it is straightforward to see that Propositions 3-7 remain valid also for the case in which $R \& D$ investments are set directly by the governments.

Second, countries have so far been assumed to be identical. Countries may differ along a number of dimensions, for example, with respect to climate costs, size, technology diffusion and income. At least for some of these factors, for example, the technology diffusion parameter, it is easy to derive formulas that are not based on identical countries. However, our main results would not change.

Third, we have assumed that all countries participate in the technology agreement. We suspect that our main results would not change of there in addition to the cooperating countries was a group of countries that did not have any, or only marginal, R\&D investments (typically, a group of developing countries). One could thus interpret our cooperating countries as some relatively small group of large countries, for example, China, the EU, Japan and USA, which stand for a major part of global R\&D expenses.

A possible topic for future research could be to endogenise the number of participating countries in an international environmental agreement (IEA). One approach is to endogenise the number of signatories through applying the 'standard' IEA model in which countries decide in the first stage of the game whether they will participate in the IEA, whereas in the second stage the group of signatory countries chooses abatement in order to maximize welfare of the IEA member countries, see, for example, Barrett (1994) and Finus (2001). Within this framework the equilibrium number of signatories is typically small. In addition, if costs or benefits change so that the potential net benefit of cooperation increases, the number of signatories shrinks. Both of these unwarranted properties may call for a new approach of modelling IEAs.

Several factors may be of importance in explaining how an IEA should be designed in order to attract broad participation. For example, burden sharing and lobbying are factors that 
may play a role in determining the number of participating countries. In fact, these factors may favour technology agreements over emission based agreements, that is, quota or tax agreements: under an emission agreement, some sectors will bear a disproportionately high share of total abatement costs. Workers and owners in such sectors will often be successful in lobbying against stringent abatement measures, thus making it difficult to reach an international agreement that substantially reduces emissions.

In contrast, the costs of technology development will typically be more evenly shared by everyone in the economy as they will be borne by the taxpayer to finance public $R \& D$ or to give tax breaks/subsidies to private firms investing in R\&D. Some sectors of the economy producing 'knowledge' will even gain from such technology development, and might thus engage in lobbying for a technology agreement. These arguments suggest that it might be easier to obtain broad participation in a technology agreement than in an emission agreement.

Finally, we have also a simplifying assumption related to verifiability. Under a technology agreement, the common technology subsidy internalizes that improved technology in one country is beneficial also for other countries. The common technology subsidy in a technology agreement is therefore higher than the technology subsidy each country would have offered to its domestic firms in the case without an international climate agreement. Because each country prefers-based on pure self-interest—a lower subsidy than the one dictated by the agreement, each country has an incentive to set various non-verifiable domestic policy instruments so that the country achieves its individually rational level of the technology subsidy. This may be possible, at least to some extent, because technology policies are often an integral part of a country's tax system, making it really hard, if possible at all, for an international agency to verify all aspects of other countries' R\&D policies.

In contrast, carbon emissions are easy to calculate, for example, based on fossil fuel use: using various sources of statistics, an international agency can determine whether a country has honoured an emission agreement or not. Thus, the limited verifiability of a technology subsidy suggests, cet. par., that a technology agreement is less efficient than an emission based agreement.

There is also another problem of verifiability when R\&D investments are subsidized, or more generally, when $R \& D$ firms receive government support. $R \& D$ is a vague concept, and it is therefore hardly feasible to define $\mathrm{R} \& \mathrm{D}$ in such a way that an agency (regulator) can clearly distinguish between $R \& D$ activities and non-R\&D activities. Therefore, when firms face an R\&D subsidy (or some other instruments that spur their R\&D activity) they have an incentive to categorize more activities as $\mathrm{R} \& \mathrm{D}$, thereby receiving a higher amount of subsidies than intended. Note, however, that under an international emission based agreement where the R\&D policy of a country is determined at the national level, it will typically be optimal to offer some type of support to the domestic R\&D firms because the social returns to $R \& D$ may by far exceed the private returns ( $k<1$ in our model). Therefore, the verifiability problem at the firm level is present both under R\&D based and emission based agreements.

Obviously, the non-verifiability problem of a technology agreement weakens the case for placing too much emphasis on international technology cooperation. But it does not suggest that it is optimal to fully disregard international R\&D cooperation. Overall, our results and discussion suggest that some steps towards including technology elements in an international climate agreement-even in an imperfect manner-may be a valuable supplement to emission based agreements. Thus, a topic for future research is to explore design of international climate agreements that are both emission and technology based when there is hidden information at the national/firm level. 


\section{Appendix}

Below we use a simple model to study under what conditions $R_{e y}(e, y)<0$. We distinguish between three types of technology progress; increased energy efficiency, lower costs of noncarbon energy and lower costs of carbon capture and storage (CCS). We let each type of technology improvement be represented through a technology variable, which is treated as an input.

Let $E$ be effective energy:

$$
E=E\left(y_{E}, \phi(F, G)\right),
$$

that is, effective energy a composite good produced by fossil $(F)$ and non-fossil $(G)$ energy. In addition, the amount of effective energy is increasing in the technology variable $y_{E}\left(E_{1}>0\right)$, reflecting increased energy efficiency. The energy input $E$ is used together with a vector of other inputs $v$-typically different types of materials— to produce gross output $\Phi(v, E)$. Let $Q$ be net output in the economy:

$$
Q=\Phi(v, E)-p_{F} F-q\left(y_{G}\right) G-C\left(F-e, y_{C}\right)-p_{v} v .
$$

Net output $Q$ is obtained by subtracting the costs of using fossil energy $p_{F} F$, the cost of using non-fossil energy $q\left(y_{G}\right) G$, the cost of CCS $C\left(F-e, y_{C}\right)$, and the costs of other inputs $p_{v} v$ from gross output $\Phi(v, E)$. The cost of non-fossil fuels is lower the higher is the technology variable $y_{G}\left(q_{G}<0\right)$, and the cost of CCS is lower the higher is the technology variable $y_{C}$ $\left(C_{2}<0\right)$. Emissions are denoted $e$, and these are measured in the same unit as fossil energy $F$. Hence, $F-e$ is abatement.

Next, we define the income function

$$
R\left(e, y_{G}, y_{C}, y_{E}\right)=\max _{F, G, v}\left\{\Phi(v, E)-p_{F} F-q\left(y_{G}\right) G-C\left(F-e, y_{C}\right)-p_{v} v\right\}
$$

With reasonable assumptions on the underlying functions above, $R\left(e, y_{E}, y_{G}, y_{C}\right)$ will be strictly concave and increasing in its arguments. To check whether it is reasonable that marginal productivity of fossil energy, $R_{e}\left(e, y_{E}, y_{G}, y_{C}\right)$, is declining in the three technology variables, we shall consider three simplified versions of the model.

\section{Increased Energy Efficiency}

Increased energy efficiency is sometimes vaguely described as the possibility of producing the same output with lower energy input. However, if increased energy efficiency can only be achieved by using more of other inputs, e.g., capital, this is simply a substitution effect. Increased energy efficiency can be defined as the possibility of producing the same output with lower energy input without increasing the use of other factors of production.

In order to focus on energy efficiency we ignore non-fossil energy and CCS, and assume that the net income function is given by

$$
R\left(e, y_{E}\right)=\Omega\left(\alpha\left(y_{E}\right) e\right)-p_{F} e
$$

where $\Omega^{\prime}>0$ and $\Omega^{\prime \prime}<0$. Increased energy efficiency is thus modelled as fossil energy augmenting technology improvement through $\alpha\left(y_{E}\right)$, which is assumed increasing in $y_{E}$. It is straightforward to derive that $R_{e y}<0$ if and only if $\Omega^{\prime}+\alpha\left(y_{E}\right) e \Omega^{\prime \prime}<0$. This inequality holds if and only if the price elasticity of $e$ with respect to $p_{F}$ (measured positively) is less than 1, that is, if $E l_{p_{F}}(-e)=\frac{\Omega^{\prime}}{-\alpha\left(y_{E}\right) e \Omega^{\prime \prime}}<1$, where the elasticity is defined at the point 
where $R_{e}=0 .{ }^{8}$ The magnitude of this price elasticity is an empirical question, yet we find it reasonable that it is below one: most empirical studies of energy demand find price elasticities lower than one, see, for example, appendix B in Aune et al. (2008) and Kilian (2008).

\section{Reduced Costs of Non-carbon Energy}

Non-carbon energy, for example, hydropower, nuclear, solar, wind and bio-energy, are imperfect substitutes for carbon (fossil) energy. Technology improvements that lower the costs of non-carbon energy will typically increase the use of this type of energy, whereas the use of carbon energy will decline for a given level of output. However, reduced cost of non-carbon energy will typically raise output, tending to increase the use of carbon energy. We therefore want to examine under what conditions the former effect dominates. To this end we ignore increased energy efficiency and CCS, and assume that the net income function is given by

$$
R\left(e, y_{G}\right)=\max _{G}\left\{\Theta(e, G)-p_{F} e-q\left(y_{G}\right) G\right\}
$$

where $\Theta$ is increasing in its arguments and strictly concave, and $q\left(y_{G}\right)$ is declining in $y_{G}$. For an interior solution for $G$, we have $\Theta_{G}(e, G)=q\left(y_{G}\right)$, which implicitly defines the function $G=G\left(e, y_{G}\right)$ where $G_{y}>0$. It is straightforward to derive that $R_{e y}=\Theta_{e G} G_{y}$, which is negative if and only if $\Theta_{e}<0$. Further, the relation $R_{e}=\Theta_{e}\left(e, G\left(e, y_{G}\right)\right)-p_{F}=0$ implicitly defines $e=e\left(p_{F}, y_{G}\right)$ where $e_{p_{F}}<0$ because of concavity. We also have $G_{e}<0$ if and only if $\Theta_{e G}<0$. Hence, $R_{e y}<0$ if and only if demand for non-carbon energy $G\left(e\left(p_{F}, y_{G}\right), y_{G}\right)$ is increasing in the price of carbon energy $p_{F}$; a higher price of carbon energy will reduce emissions $\left(e_{p_{F}}<0\right)$, which will increase non-carbon energy $G$ if and only if $\Theta_{e G}<0$, which is a sufficient condition for $R_{e y}<0$. We think the condition $\Theta_{e G}<0$ is reasonable because typically carbon and non-carbon energy are substitutes.

\section{Reduced Costs of Carbon Capture and Storage (CCS)}

Finally, we focus on reduced costs of CCS, that is, we ignore improved energy efficiency and lower costs of non-carbon energy. CCS will always have some costs, and will thus not be used if there are no restrictions on emissions. In that case, a lower CCS cost will not have any effect on $\mathrm{BaU}$ output. On the other hand, if restrictions on emissions are sufficiently strict, for example, if there is a sufficiently high carbon tax on emissions, then CCS will be used, and reduced cost of CCS will increase its use.

We now examine the impact on the amount of carbon energy of lower costs of CCS. Assume that the net income function is given by

$$
R\left(e, y_{C}\right)=\max _{F}\left\{\Psi(F)-p_{F} F-\beta\left(y_{C}\right) \chi(F-e)\right\}
$$

where $\Psi^{\prime}>0, \Psi^{\prime \prime}<0, \chi^{\prime}>0, \chi^{\prime \prime}>0$ and the variable $\beta\left(y_{C}\right)$ is assumed to be declining in $y_{C}$. The optimal amount of fossil energy is given by $\Psi^{\prime}(F)=\beta\left(y_{C}\right) \chi^{\prime}(F-e)+p_{F}$, which implicitly defines the function $F=F\left(e, y_{C}\right)$ where $F_{y}>0$. From the envelope theorem we have $R_{e}=\beta\left(y_{C}\right) \chi^{\prime}(F-e)=\Psi^{\prime}\left(F\left(e, y_{C}\right)\right)-p_{F}$. Thus $R_{e y}=\Psi^{\prime \prime}(F) F_{y}$, which is negative under our assumptions. Hence, $R_{e y}<0$ under the assumptions of a concave production function and marginal costs of CCS being increasing in abatement $\left(\chi^{\prime \prime}>0\right)$. We believe the latter condition is reasonable, for example, because costs of transporting removed carbon to the storage site differ between plants (transport length to the storage site differs), or because

8 This result also holds if gross output is given by $\Phi\left(\alpha\left(y_{E}\right)^{\beta} e^{1-\beta}\right)$. 
CCS is more costly for small stationary sources than for large stationary sources (different technologies).

Open Access This article is distributed under the terms of the Creative Commons Attribution Noncommercial License which permits any noncommercial use, distribution, and reproduction in any medium, provided the original author(s) and source are credited.

\section{References}

Aune FR, Golombek R, Kittelsen SAC, Rosendahl KE (2008) Liberalizing European energy markets. An economic analysis. Edward Elgar, Cheltenham

Barrett S (1994) Self-enforcing international environmental agreements. Oxford J Econ 88:312-319

Barrett S (2003) Environment and statecraft: the strategy of environmental treaty-making. Oxford University Press, Oxford

Barrett S (2006) Climate treaties and "breakthrough" technologies'. Am Econ Rev Papers Proc 96(2):22-25

Böhringer C, Vogt C (2003) Economic and environmental impacts of the Kyoto Protocol. Can J Econ 36(2):475-494

Cohen WM, Levinthal DA (1989) Innovation and learning: the two faces of R\&D. Econ J 99:569-596

Cooper R (1998) Toward a real global climate treaty. For Aff 77:66-79

Finus M (2001) Game theory and international environmental cooperation. Edward Elgar, Cheltenham, UK and Northampton, USA

Fischer C, Parry IWH, Pizer WA (2003) Instrument choice for environmental protection when technological innovation is endogenous. J Environ Econ Manag 45:523-545

Golombek R, Hoel M (2004) Unilateral emission reductions and cross-country technology spillovers. Adv Econ Anal Policy 4(2):Article 3. (http://www.bepress.com/bejeap/advances/vol4/iss2/art3)

Golombek R, Hoel M (2006) Second-best climate agreements and technology policy. Adv Econ Anal Policy 6(1):Article 1. (http://www.bepress.com/bejeap/advances/vol6/iss1/art1)

Jung C, Krutilla K, Boyd R (1996) Incentives for advanced pollution abatement technology at the industry level: an evaluation of policy alternatives. J Environ Econ Manag 30:95-111

Katsoulacos Y, Ulph D (1998) Endogenous spillovers and the performance of research joint ventures. J Indus Econ XLVI(3):333-357

Kilian L (2008) The economic effects of energy price shocks. J Econ Lit 46(4):871-909

Milliman SR, Prince R (1989) Firm incentives to promote technological change in pollution control. J Environ Econ Manag 17:247-265

Popp D (2004) ENTICE: endogenous technological change in the DICE model of global warming. J Environ Econ Manag 48(1):742-768

Popp D (2006) Innovation in climate policy models: implementing lessons from the economics of R\&D. Energy Econ 28:596-609

Sena V (2004) The return of the prince of Denmark: a survey on recent developments in the economics of innovations. Econ J 114(June):312-332

Spence M (1984) Cost reduction, competition and industry performance. Econometrica 52:101-122

Victor DG (2001) The collapse of the Kyoto protocol and the struggle to slow global warming. Princeton University Press, Princeton

Victor DG, Coben LA (2005) A herd mentality in the design of international environmental agreements? Glob Environ Politics 5:24-57

Wiener JB (1999) Global environmental regulation: instrument choice in legal context. Yale Law J 108: $677-800$ 